\title{
Transgenic Mice Expressing Shb Adaptor Protein under the Control of Rat Insulin Promoter Exhibit Altered Viability of Pancreatic Islet Cells
}

\author{
Michael Welsh, Lars Christmansson, Torbjörn Karlsson, \\ Stellan Sandler, and Nils Welsh \\ Department of Medical Cell Biology, Uppsala University, Uppsala, \\ Sweden \\ Communicated by D. Steiner. Accepted February 4, 1999.
}

\begin{abstract}
Background: The Src-homology 2 domain-containing adaptor protein Shb was recently cloned as a seruminducible gene in the insulin-producing $\beta$-TCl cell line. Subsequent studies have revealed an involvement of Shb for apoptosis in NIH3T3 fibroblasts and differentiation in the neuronal PC 12 cells. To assess a role of Shb for $\beta$-cell function, transgenic mice utilizing the rat insulin promoter to drive expression of Shb were generated.

Materials and Methods: A gene construct allowing the Shb cDNA to be expressed from the rat insulin 2 promoter was microinjected into fertilized mouse oocytes and implanted into pseudopregnant mice. Mice containing a low copy number of this transgene were bred and used for further experimentation. Shb expression was determined by Western blot analysis. The insulin-positive area of whole pancreas, insulin secretion of isolated islets and islet cell apoptosis, glucose tolerance tests, and in vivo sensitivity to multiple injections of the $\beta$-cell toxin streptozotocin were determined in control CBA and Shb-transgenic mice.

Results: Western blot analysis revealed elevated islet content of the Shb protein. Shb-transgenic mice dis-

played enhanced glucose-disappearance rates in response to an intravenous glucose injection. The relative pancreatic $\beta$-cell area neonatally and at 6 months of age were increased in the Shb-transgenic mice. Islets isolated from Shb-transgenic mice showed enhanced insulin secretion in response to glucose and increased insulin and DNA content. Apoptosis was increased in islets isolated from Shb-transgenic mice compared with control islets both under basal conditions and after incubation with IL- $1 \beta+$ IFN- $\boldsymbol{\gamma}$. Rat insulinoma RINm5F cells overexpressing Shb displayed decreased viability during culture in $0.1 \%$ serum and after exposure to a cytotoxic dose of nicotinamide. Shb-transgenic mice injected with multiple doses of streptozotocin showed increased blood glucose values compared with the corresponding controls, suggesting increased in vivo susceptibility to this toxin. Conclusion: The results suggest that $\mathrm{Shb}$ has dual effects on $\beta$-cell growth: whereas Shb increases $\beta$-cell formation during late embryonal stages, Shb also enhances $\beta$-cell death under certain stressful conditions and may thus contribute to $\beta$-cell destruction in type 1 diabetes.
\end{abstract}

\section{Introduction}

The adult pancreatic $\beta$ cell has a limited capacity for regeneration, and this could be of rele-

Address correspondence and reprint requests to: Dr. Michael Welsh, Department of Medical Cell Biology, Box 571, Biomedicum, SE-75123 Uppsala, Sweden. Phone: 46-184714505; Fax: 46-18-556401; E-mail:

michael.welsh@medcellbiol.uu.se

vance for the development of diabetes mellitus (1). Much attention has been given to the control of $\beta$-cell formation (2) and it is presently clear that the active $\beta$-cell mass is a function of replication of pre-existing $\beta$ cells, $\beta$-cell neoformation from precursor cells, and $\beta$-cell survival. In search of signaling pathways controlling $\beta$-cell replication, we recently partially characterized the SH2 (Src homology 2) do- 
main-containing adaptor protein Shb from $\beta T C-1$ cells (3). Although we have subsequently demonstrated molecular interactions of the Shb SH2 domain with the platelet-derived growth factor (PDGF) $\beta$-receptor, the fibroblast growth factor (FGF) receptor-1, and the $\mathrm{T}$ cell receptor $(4,5)$, the Shb proline-rich motifs with Src, Eps8, p85 PI3-kinase, and Grb2 $(4,5)$, and the central phosphotyrosinebinding (PTB) domain with $\mathrm{p} 36 / 38$ in Jurkat $\mathrm{T}$ cells (5), the physiological significance of Shb remains elusive. Shb overexpression in NIH3T3 cell fibroblasts causes increased rates of apoptosis upon serum withdrawal, an effect counteracted by PDGF (6). Furthermore, Shb plays a role for $\mathrm{T}$ cell receptor signaling in Jurkat $\mathrm{T}$ cells (5), whereas Shb overexpression in neuronal PC12 cells enhances growth factor-induced differentiation (7). Thus it appears that $\mathrm{Shb}$ plays a role in regulating a multitude of responses, each specific for a certain type of cell.

The present study was performed to establish a role of $S h b$ for $\beta$-cell function. For this purpose, a transgenic mouse with Shb under the control of the rat insulin 2 promoter (8) was generated. We determined the $\beta$-cell area, insulin secretion, and apoptosis in response to the cytokines interleukin- $1 \beta$ (IL- $1 \beta)+$ interferon $\gamma($ IFN- $\gamma$ ) of these Shb-transgenic mice. The responses to the cytokines were tested since these have been suggested to play a role for $\beta$-cell destruction in type 1 diabetes $(9-11)$. Furthermore, the development of hyperglycemia in mice injected with multiple low doses of the $\beta$-cell toxin streptozotocin was determined. The results suggest that Shb may contribute to $\beta$-cell destruction under certain conditions.

\section{Materials and Methods}

\section{Construction of Transgene}

The $2.3 \mathrm{~kb}$ Shb cDNA was excised by EcoRI cleavage and inserted into XbaI-HindIII cleaved RIP1plasmid (8) after blunt-end formation. This construct contains sequences corresponding to 0.6 $\mathrm{kb}$ of the rat insulin 2 promoter, $2.3 \mathrm{~kb}$ of the Shb cDNA, and $0.5 \mathrm{~kb}$ of SV40 small t intron including a polyA signal. Plasmid sequences were excised by AatII + SalI digestion. The transgene was microinjected into fertilized CBA mouse oocytes and then implanted in pseudopregnant CBA mice of a local stock at Umeå University (Umeå, Sweden). Incorporation of the transgene into the genome of the offspring was verified by Southern blot analysis of BamHI-digested DNA prepared from tissue samples of 3-week-old mice, using $\left[{ }^{32} \mathrm{P}\right]$-labeled Shb cDNA as a probe. Two founder mice, each containing a low copy number of the transgene (1-3 copies per genome), were obtained. These were used to create two RIP1-Shb transgenic lineages of mice that were bred separately. The typical offspring from two transgenic breeders consisted of $70 \%$ transgenic mice (containing 1-3 copies of the transgene per genome) and $30 \%$ that were devoid of the transgene. We have failed to obtain mice homozygous for the RIP-Shb transgene. The transgenic lineages have been maintained thus far for more than six generations. For experimentation, RIP1Shb transgenic mice of both sexes and from both lineages and all generations at day 1 neonatally or 3 months of age were used. Owing to difficulties in obtaining sufficiently large numbers of age-matched transgenic (of either lineage) or control mice, the experiments could not be performed for each RIP-Shb transgenic lineage independently. The phenotypic characteristics of the Shb-transgenic mice appear normal except for the differences described below. All animal experimentation was approved by the Institutional Review Board for Animal Experimentation.

\section{Islet Isolation and Further Experimentation}

Islets were isolated from control CBA or RIP1Shb transgenic 3-month-old mice of both sexes and cultured for $18 \mathrm{hr}$ in the presence of 1 or $10 \%$ fetal calf serum (FCS) with or without the addition of cytokines $[25 \mathrm{U} / \mathrm{ml}$ of human $\mathrm{IL}-1 \beta$ (PeproTech, London, UK) $+1000 \mathrm{U} / \mathrm{ml}$ of murine IFN- $\gamma$ (R\&D Systems, Abingdon, UK)]. The islets were then used for determination of insulin secretion, insulin content, DNA content, and apoptosis by TUNEL (terminal deoxynucleotidyl transferase-mediated dUTP nick end-labeling) staining (12-15). The percentage of insulin-positive relative to total pancreas area was determined at day 1 after birth or at the age of 6 months by staining sections for insulin using an unlabeled peroxidase-antiperoxidase technique (16). The insulin-positive area was determined on one cross section each from four to five different neonatal pancreata, and three cross sections from different regions (caput, corpus, and 
cauda) of each 6-month-old pancreas, using a computerized image analysis system for morphometry (MOP Videoplan, Kontron Bildanalyse, Munich, Germany). Labeling index of insulin-positive cells in vivo was also assessed at the age of 3 months (17).

\section{Glucose Homeostasis}

Shb-transgenic and control CBA mice of 3 or 6 months of age were injected intravenously with 0.42 mmole of glucose, after which blood glucose was determined on samples collected from the animals' tails at the time points indicated (ExacTech Blood Glucose Meter, Baxter Travenol, Deerfield, IL). Glucose disappearance rates were calculated as previously reported (18).

\section{RINm5F Cells Overexpressing Shb}

RINm5F cells were transfected with Shb cDNA in the expression vector pcDNAl using the Lipofectamine ${ }^{\mathrm{TM}}$ method (6) and clonal selection was performed in the presence of $0.3 \mathrm{mg} / \mathrm{ml}$ geneticin. In parallel, cells were transfected with the neomycin resistance gene only (RIN-neo) for generating appropriate control cells. Fifteen clones transfected with the Shb cDNA were analyzed for Shb expression by Western blot analysis, and one of these was found to contain significantly elevated content of Shb (RIN-Shb). For the determination of apoptosis, cells were stained for $10 \mathrm{~min}$ at $37^{\circ} \mathrm{C}$ with $10 \mu \mathrm{g} / \mathrm{ml}$ propidium iodide and $20 \mu \mathrm{g} / \mathrm{ml}$ Hoechst 33342, after which the cells were inspected in a fluorescence microscope using a UV-2A filter.

\section{Injections of Multiple Doses of Streptozotocin}

Shb-transgenic and CBA control mice of both sexes and 3 months of age were injected intraperitoneally with five daily doses of $40 \mathrm{mg} / \mathrm{kg}$ body mass streptozotocin or saline $(0.2 \mathrm{ml})$. Blood glucose values were determined weekly, starting with the first injections. At 3 weeks, the animals were killed and pancreatic insulin content was determined after acid ethanol extraction from a weighed part of the retrieved pancreata.
A.

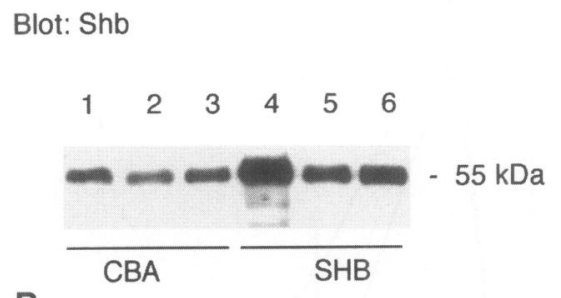

B.

Blot: Shb
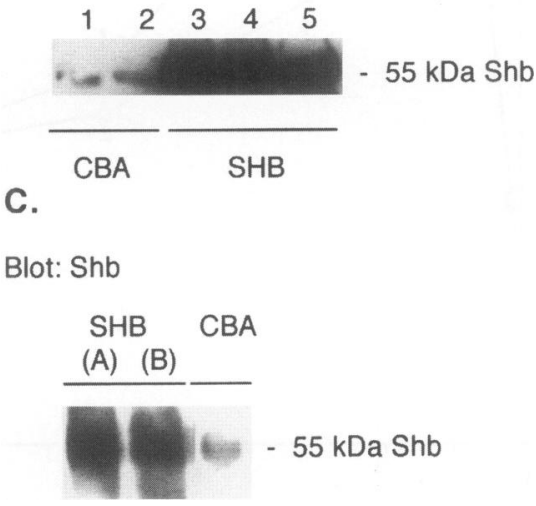

Fig. 1. Shb-protein expression in transgenic and control CBA islets. (A) Expression of Shb in islets isolated from Shb-transgenic and control CBA mice. Islets were isolated and dissolved in SDS sample buffer before boiling and electrophoresis and Western blot analysis for Shb protein as previously described (6). Each lane represents the protein extract of about 50 islets from one animal. Equal amounts of protein were electrophoresed in the lanes. (B) CBA islets $(1,2)$ or RIP-Shb islets (3-5) were pretreated for $30 \mathrm{~min}$ at $37^{\circ} \mathrm{C}$ with $20 \mu \mathrm{M} \mathrm{N}$ acetyl-leu-leu-norleucinal prior to electrophoresis and Western blot analysis as in A. Each lane shows the extract of 20 islets. Equal amounts of protein were electrophoresed in lanes 1-5. (C) CBA or Shbtransgenic islets from lineages $\mathrm{A}$ and $\mathrm{B}$ were pretreated, lysed, and subjected to Western blot analysis as in B. Lysate from 20 islets was electrophoresed in each lane.

\section{Statistical Analysis}

The means \pm SEM for the number of observations are given. Each observation is based on the value obtained from one animal or one individual islet isolation. Cell countings or staining for apoptosis was performed at separate time points for each observation. Comparisons were made using the paired or unpaired Students' $t$-test. 

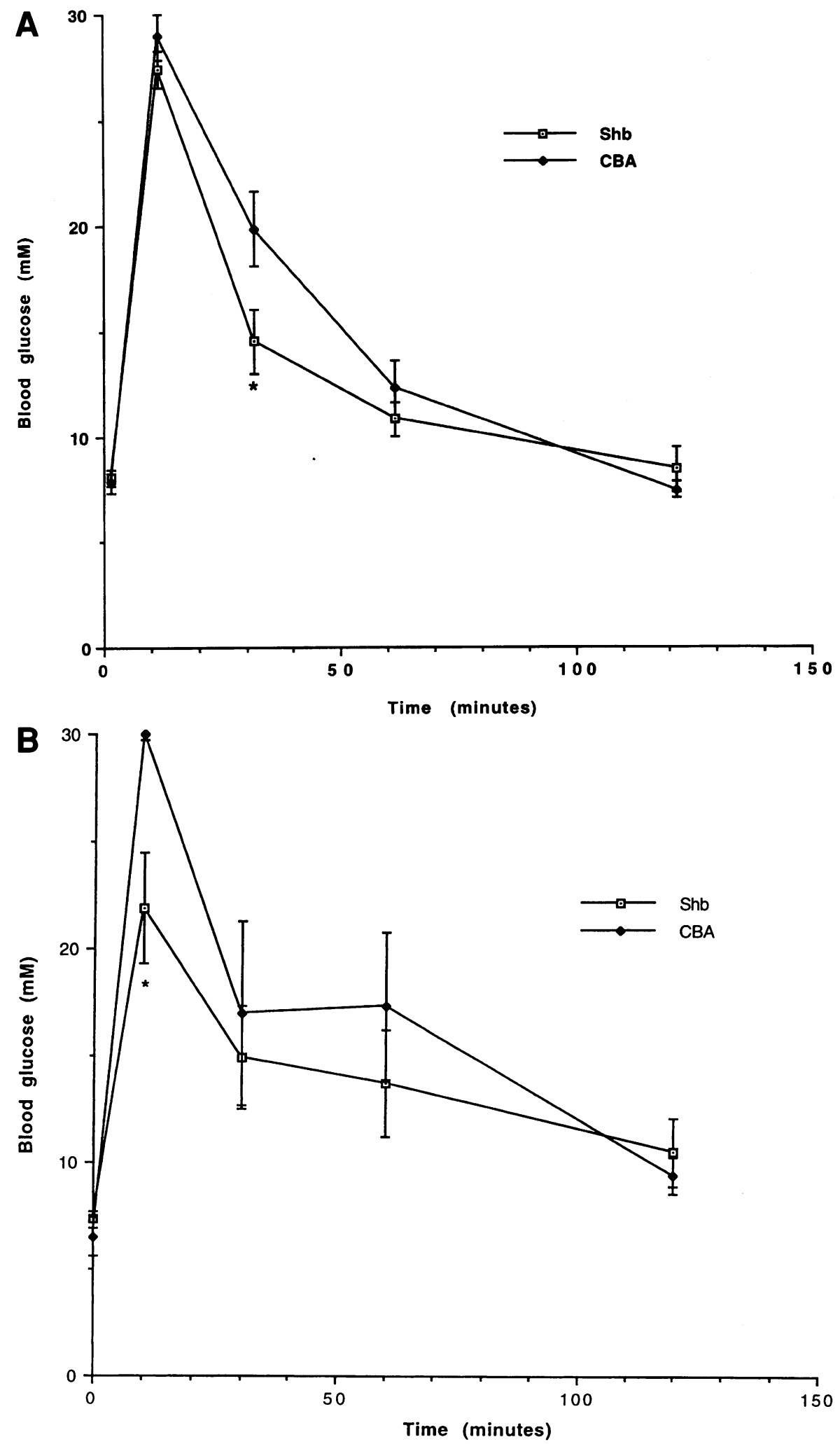

Fig. 2. Blood glucose levels of control CBA and Shb-transgenic mice. (A) Blood glucose profiles after an intravenous glucose injection of Shb-transgenic $(n=$ 9) and CBA ( $n=7)$ mice. Data for mean \pm SEM are given. ${ }^{*} p<0.05$ when compared with the corresponding 30-min value of CBA mice with an unpaired Student's $t$-test. (B) Blood glucose profiles, as in $A$, in 6-month-old mice. Data for mean \pm SEM for 5 experiments are shown. ${ }^{*} p<0.05$ using an unpaired Students' $t$-test when compared with the corresponding CBA value. 
Table 1. $\beta$-cell area and labeling index in Shb-transgenic and CBA mice

\begin{tabular}{lllc}
\hline & $\begin{array}{c}\boldsymbol{\beta} \text {-Cell Area (\%) } \\
\text { Day 1 Neonatally }\end{array}$ & $\begin{array}{c}\boldsymbol{\beta} \text {-Cell Area (\%) } \\
\text { 6 Months of Age }\end{array}$ & $\begin{array}{c}\text { Labeling Index (\%) } \\
\text { 3 Months of Age }\end{array}$ \\
\hline $\mathrm{CBA}$ & $0.79 \pm 0.18(n=5)$ & $0.76 \pm 0.16(n=4)$ & $2.38 \pm 0.76(n=3)$ \\
$\mathrm{Shb}$ & $1.58 \pm 0.26^{*}(n=4)$ & $1.34 \pm 0.16^{*}(n=4)$ & $2.59 \pm 0.71(n=3)$ \\
\hline
\end{tabular}

$\beta$-cell area is the percentage of insulin-positive area relative to that of total pancreas area determined at day 1 neonatally or 6 months of age for CBA control or Shb transgenic mice. The labeling index values are percent insulin-positive cells with nuclei that have incorporated $\left[{ }^{3} \mathrm{H}\right]$-thymidine of animals injected with the isotope at 3 months of age.

${ }^{*} p<0.05$ using an unpaired Student's $t$-test when compared with CBA control.

Table 2. Insulin and DNA content of islets isolated from Shb-transgenic mice

\begin{tabular}{lccc}
\hline & $\begin{array}{c}\text { Insulin } \\
\text { Content } \\
\text { (ng/10 islets) }\end{array}$ & $\begin{array}{c}\text { DNA } \\
(\boldsymbol{\mu g} / 10 \text { islets) }\end{array}$ & $\begin{array}{c}\text { Insulin/DNA } \\
\text { (ng/ng) }\end{array}$ \\
\hline CBA & $225 \pm 21$ & $0.17 \pm 0.02$ & $1.37 \pm 0.11$ \\
Shb & $340 \pm 42^{*}$ & $0.26 \pm 0.03^{*}$ & $1.36 \pm 0.11$ \\
\hline
\end{tabular}

Islets were isolated from control CBA mice and Shb-transgenic mice of both sexes and at age 3 months and maintained in tissue culture for $18 \mathrm{hr}$ after which insulin content and DNA content were determined. Values are mean \pm SEM for 7 to 9 observations.

${ }^{*} p<0.05$ when compared with corresponding value of CBA control islets using an unpaired Student's $t$-test.

\section{Results}

\section{Expression of Transgene Product}

Islets isolated from Shb-transgenic and CBA control mice contained moderately elevated contents of the $55 \mathrm{kD}$ Shb protein (Fig. 1A) as determined by Western blot analysis of islet lysates using an Shb-reactive antibody (6). Densitometric analysis (in arbitrary absorbance units) revealed an increase in Shb content from $0.58 \pm 0.04$ in the control islets to $1.17 \pm$ 0.16 in the transgenic islets $(p<0.05$ with an unpaired Student's $t$-test, $n=3$ ). When islets isolated from control CBA and Shb-transgenic mice were preincubated for $30 \mathrm{~min}$ in the presence of $20 \mu \mathrm{M}$ of the protease inhibitor $\mathrm{N}$ acetyl-leu-leu-norleucinal before being dissolved in SDS sample buffer, the Shb-protein expression of Shb-transgenic islets relative to that of control islets increased dramatically (Fig. 1B), compared with islets that had not been pretreated with protease inhibitors (Fig. 1A). Thus, islet cells overexpressing the Shb mRNA display mechanisms for proteolytic down-regulation of the Shb protein.

The degree of islet Shb-protein expression was determined in both lineages of Shb-transgenic mice (Fig. 1C). Western blot analysis of islet lysates revealed a comparable degree of Shbprotein overexpression in Shb-transgenic mouse islets from both lineages $\mathrm{A}$ and $\mathrm{B}$ when compared with CBA control islets (Fig. 1C), supporting the view that the Shb-transgenic phenotype is independent of the site of transgene integration.

\section{Glucose Homeostasis}

The basal blood glucose levels of control CBA and Shb-transgenic mice of both sexes was similar and below $8 \mathrm{mM}$ in both groups of animals. Glucose injection caused a rapid increase in blood glucose to above $25 \mathrm{mM}$ at 10 min after administration (Fig. 2A). The blood glucose rapidly diminished after this time point, and the Shb-transgenic mice displayed a significantly lower blood glucose value at 30 min after injection than the CBA control. The calculated glucose disappearance rate (18) of the Shb-transgenic mice was $5.5 \pm 0.8 \%$ per min; the corresponding value for the CBA control mice was significantly lower $(3.0 \pm 0.4 \%$ per min; $p<0.05)$. Like the enhanced blood glucose disappearance rates of the 3-monthold Shb-transgenic mice, 6-month-old Shbtransgenic mice displayed significantly lower blood glucose values at $10 \mathrm{~min}$ after glucose injection (Fig. 2B). 


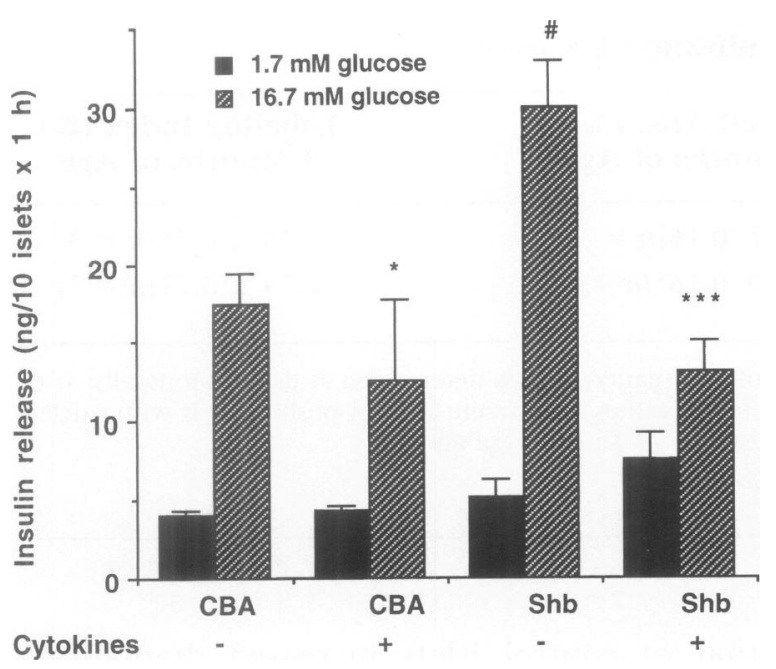

Fig. 3. Insulin secretion of islets isolated from control CBA or Shb-transgenic mice. Isolated islets were cultured in RPMI $1640+10 \%$ serum for $18 \mathrm{hr}$ in the absence or presence of $25 \mathrm{U} / \mathrm{ml} \mathrm{IL-1} \beta+$ $1000 \mathrm{U} / \mathrm{ml}$ IFN $-\gamma$. The islets were then incubated for $60 \mathrm{~min}$ in $1.7 \mathrm{mM}$ glucose, followed by an incubation for $60 \mathrm{~min}$ in $16.7 \mathrm{mM}$ glucose, after which insulin secretion was determined. Data for mean \pm SEM for 7 to 9 observations are given. $\# p<0.01$ when compared with CBA control islets in the absence of cytokines using an unpaired Students' $t$ test; ${ }^{*} p<0.05$ and ${ }^{* * *} p<0.001$ when compared with the corresponding values in the absence of cytokines using a paired Students' $t$-test.

\section{Insulin-Positive Area and $\beta$-Cell Labeling Index In Vivo}

The percentage of insulin-positive area relative to total pancreas area on day 1 neonatally was higher in the Shb-transgenic mice than in control CBA mice (Table 1). This difference in insulin-positive area persisted to the age of 6 months, without being further accentuated (Table 1). The average pancreatic weight of Shb-transgenic mice was $0.25 \pm 0.01 \mathrm{~g}(n=5)$ and the corresponding value for CBA control mice was $0.23 \pm 0.01 \mathrm{~g}(n=5)$, indicating that the increased $\beta$-cell area of the Shb-transgenic mice actually represents an increase in $\beta$-cell mass. The $\beta$-cell labeling index in vivo for 3-month-old Shb-transgenic mice was similar to that for CBA controls of the same age (Table 1).

\section{Insulin Content and Glucose-Stimulated Insulin Secretion}

The islet insulin content and DNA content were increased in the isolated Shb-transgenic

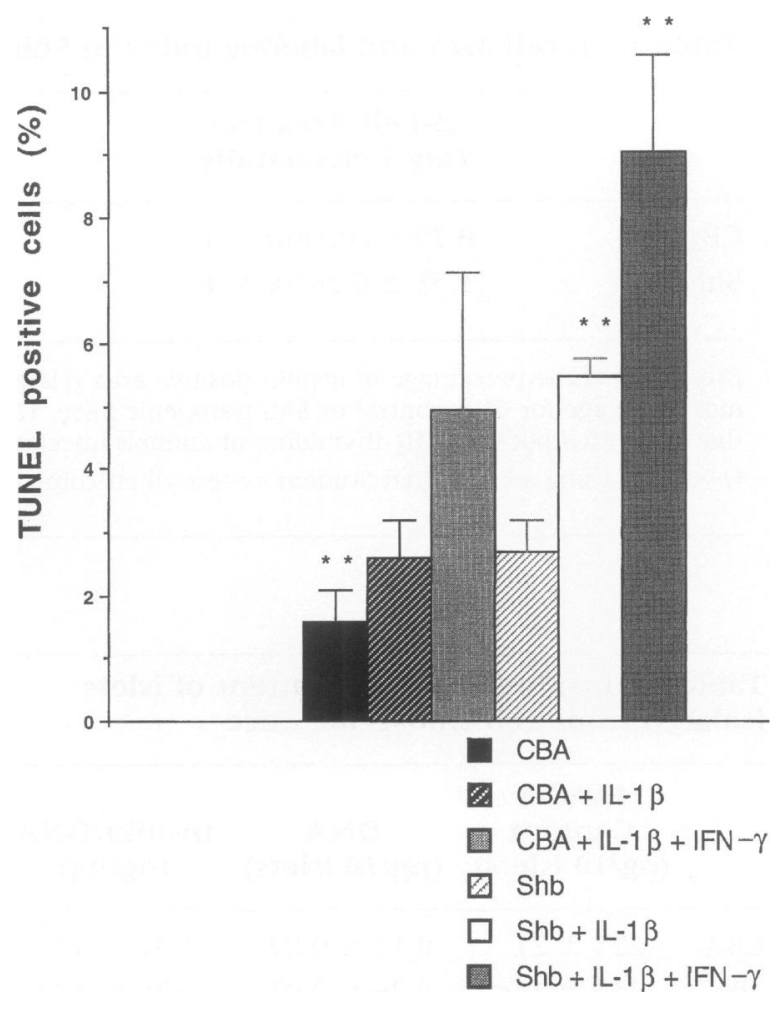

Fig. 4. Islet cell apoptosis after culture in the presence of $1 \%$ serum. Isolated islets were cultured for $18 \mathrm{hr}$ in the absence or presence of the cytokines indicated. The islets were then fixed and processed for TUNEL staining, which detects apoptosis by visualizing DNA strand breaks. Percent TUNEL-positive nuclei is given as mean \pm SEM for 4 to 5 determinations. ${ }^{* *} p<0.01$ when compared with Shb-transgenic islets in the absence of cytokines using a paired Students $t$-test.

islets at 3 months of age compared with the corresponding CBA control islets (Table 2). However, when calculating the insulin per DNA content, near-equal values were noted (Table 2). The insulin secretion of Shb-transgenic islets is shown in Figure 3. Insulin secretion in the presence of $1.7 \mathrm{mM}$ glucose was similar in all experimental groups irrespective of cytokine addition. The incubation at 16.7 $\mathrm{mM}$ glucose increased the secretion of insulin regardless of whether islets from CBA control or Shb-transgenic mice were used (Fig. 3). However, the secretion of insulin at $16.7 \mathrm{mM}$ glucose was significantly elevated in the Shbtransgenic islets compared to that of the CBA control. Culture of the islets in the presence of the cytokines IL- $1 \beta+$ IFN- $\gamma$ significantly reduced the secretion of insulin in the presence of $16.7 \mathrm{mM}$ glucose in both groups of islets (Fig. 3). 
Apoptosis of Shb-Transgenic Islets

Since we had previously reported apoptosis in NIH3T3 cells overexpressing Shb protein cultured in the presence of a low serum concentration (6), it was of interest to determine the rate of islet cell apoptosis in Shb-transgenic mice using the TUNEL technique. Islets isolated from Shbtransgenic mice exhibited a higher apoptotic index than control CBA islets after culture in $1 \%$ serum (Fig. 4). In addition, both IL- $1 \beta$ alone and the combination of IL- $1 \beta+$ IFN- $\gamma$ increased the rates of apoptosis in the Shb-transgenic islets compared with culture in the absence of cytokines.

\section{Growth and Viability of Shb-Overexpressing RINm5F Cells}

To further elucidate the effects of the Shb protein on growth and survival of insulin-producing cells in vitro, RINm5F cells were transfected with Shb cDNA. One clone overexpressing Shb (RIN-Shb) was found as determined by Western blot analysis (Fig. 5A). Since Shb was originally identified as a serum-inducible gene (3), it was of interest to determine if Shb protein expression was modified by serum withdrawal in the RIN-neo cells. The RIN-neo cells maintained for $18 \mathrm{hr}$ at $0.1 \%$ serum displayed slightly less Shb protein content than those maintained in 10\% serum (Fig. 5B). The proliferation of RIN-Shb cells compared with control transfected cells (RIN-neo) was determined in $10 \%$ serum (Fig. 5C). Both clones proliferated rapidly and no signs of decreased rates of proliferation in the RIN-Shb cells were detected.

Performing the same experiments in the presence of $0.1 \%$ serum yielded different results (Fig. 5D). Whereas the cell numbers were similar for the first $48 \mathrm{hr}$ in the RIN-neo and RIN-7 Shb cells, the number of RIN-Shb cells decreased after 72 and $96 \mathrm{hr}$ compared with the initial 24-hr value (Fig. 5D). The number of RIN-neo cells remained constant throughout the experiment. The decrease in the number of RIN-Shb cells was found to be associated with an increase in cell apoptosis. The number of apoptotic cells as assessed by propium iodide staining (19) of RIN-neo cells after culture for 3 days in $0.1 \%$ serum was $1.8 \pm 0.6 \%(n=3)$. The corresponding value increased $(p<0.05$ with an unpaired Students' $t$-test) to $5.1 \pm$ $0.9 \%(n=3)$ for the RIN-Shb cells. To deter- mine the susceptibility of RIN-Shb cells to another agent that induces apoptosis in RINm5F cells, RIN-Shb and control cells were exposed to $50 \mathrm{mM}$ nicotinamide for $20 \mathrm{hr}$ (19), after which cell viability was again assessed by propidium iodide staining. In the control cells (RIN-neo), the percentage of apoptotic nuclei was $0 \%$ in the absence of nicotinamide and $6.4 \pm 2.0 \%(n=3)$ after nicotinamide treatment. The corresponding values for the RINShb cells were $0.2 \pm 0.2 \%$ and $18.1 \pm 2.0 \%$ $(p<0.02$ with an unpaired Students' $t$-test when compared with RIN-neo cells exposed to nicotinamide), respectively. The data suggest that $\mathrm{Shb}$ overexpression decreases RINm5F cell viability in $0.1 \%$ serum and $50 \mathrm{mM}$ nicotinamide.

\section{Multiple Injections of Streptozotocin}

Multiple injections of streptozotocin in mice is a model for cytotoxic and inflammatory $\beta$-cell destruction (20). We decided to test the susceptibility of Shb-transgenic mice to this treatment. Control CBA and Shb-transgenic mice of both sexes and 3 months of age were injected with five doses of streptozotocin, which was followed by the development of hyperglycemia (Fig. 6A). The blood glucose levels at 1, 2, and 3 weeks after the start of injections were significantly higher in the Shb-transgenic mice (Fig. 6A). With regard to susceptibility to streptozotocin in these experiments, the Shb-transgenic mice of both sexes seemed to increase their blood glucose levels compared with the corresponding controls; the differences between male and female susceptibility failed to reach statistical significance except for male mice 1 week after the start of the injections (Fig. 6B). The pancreatic insulin content (pmol insulin/mg pancreas) was markedly reduced 3 weeks after starting the streptozotocin treatment in both CBA $(p<0.001)$ and Shb-transgenic $(p<0.001)$ mice compared to corresponding controls [Shb-transgenic: $48.3 \pm 4.0$ $(n=8)$; Shb-transgenic + streptozotocin: $14.8 \pm 2.8(n=10) ;$ CBA: $54.5 \pm 4.8(n=8)$; CBA + streptozotocin: $24.5 \pm 3.0(n=11)$ ]. The insulin content in the transgenic mice appeared to be lower than in the CBA mice after streptozotocin administration, but this difference did not attain statistical significance $(p<0.06$ using ANOVA). These results thus 
suggest increased $\beta$-cell destruction in vivo in response to streptozotocin in the Shb-transgenic islets.

\section{Discussion}

In order to obtain an understanding of the role of $\mathrm{Shb}$ protein for $\beta$-cell function in vivo, Shb cDNA was placed under the control of rat insulin 2 promoter and used to create transgenic mice. The Shb expression level in islets isolated from such transgenic mice was moderately elevated, and a similar degree of Shb overexpression has previously been observed in NIH3T3 cells (6) or PC12 cells (7) transfected with the Shb cDNA. We have observed expression of various Shb isoforms corresponding to molecular weights of $55,59,66$, and $77 \mathrm{kD}(6,7)$. The pancreatic islets studied here expressed primarily the 55-59 kDa Shb isoforms. Surprisingly, the modest increase in the level of Shb expression detected in the Shb-transgenic islets was greatly accentuated by preincubation of the islets with the protease inhibitor $\mathrm{N}$-acetylleu-leu-norleucinal prior to SDS-gel electrophoresis. A similar discrepancy in the expression level of Shb between cells pretreated with the protease inhibitor and untreated cells was noted when comparing RIN-Shb with RIN-neo cells (results not shown). These results can be interpreted to suggest that Shb protein overexpression is down-regulated by proteolysis in islet or RINm5F cells. Two founder mice with insertion of the transgene were obtained, and for practical reasons, the data presented are based on a mixture of animals or islets from both lineages. The degree of Shb overexpression is very similar in both lineages and we have not noticed any apparent differences in the various responses studied between these lineages. Thus we conclude that the results are representative for overexpression of Shb protein regardless of the site of integration of the transgene.

$\mathrm{Shb}$ is an adaptor protein involved in tyrosine kinase signaling $(3,4)$, and on the basis of most of the knowledge accumulated in this field of research, one would expect Shb to be involved in one or several aspects of cell proliferation, differentiation, migration, and survival (21). Our data on Shb overexpression in NIH3T3 cells suggest that Shb plays a role in
A

Blot: Shb
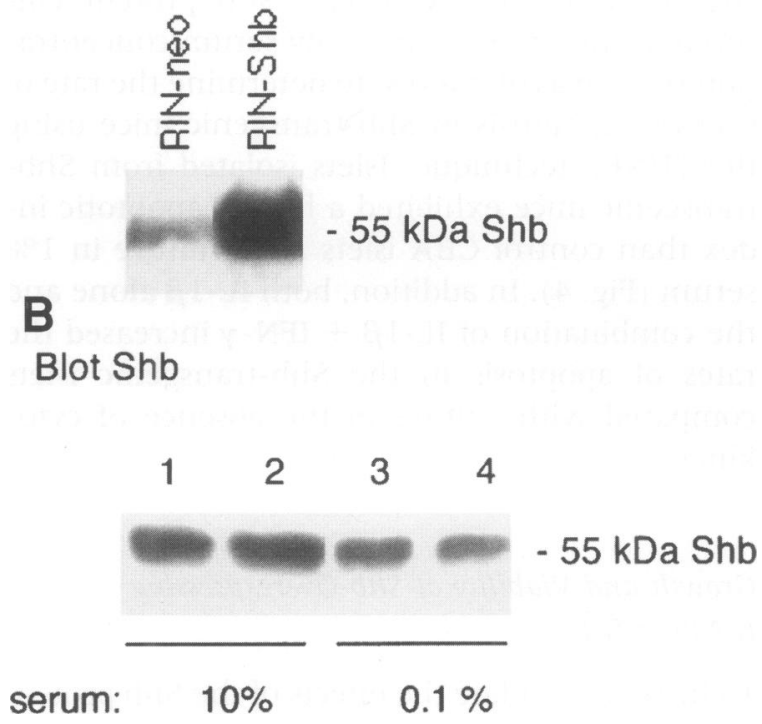

Fig. 5. Shb expression and cell proliferation of RIN-Shb and RIN-neo cells. (A) Exponentially growing cells were preincubated for 30 min with 20 $\mu \mathrm{M} \mathrm{N}$-acetyl-leu-leu-norleucinal, scraped and collected, and lysed in SDS sample buffer. The samples were boiled and equal amounts of protein from the RIN-Shb and RIN-neo cells were electrophoresed. After Western transfer, the blot was incubated with Shb-antibody and subjected to ECL detection as in Fig. 1. (B) Effects of serum on Shb expression. Equal amounts of RIN-neo cell were plated in four dishes and maintained in $10 \%$ serum for $24 \mathrm{hr}$. Two dishes $(1,2)$ were cultured for an additional $18 \mathrm{hr}$ in $10 \%$ serum whereas the other two $(3,4)$ were maintained in $0.1 \%$ serum for $18 \mathrm{hr}$. The cells were collected and subjected to Western blot analysis for Shb protein expression as in Fig. 1. (C) Growth of RIN-Shb and RIN-neo cells in $10 \%$ serum. Cells $(30,000)$ were plated after trypsinization and cultured in $1 \mathrm{ml}$ RPMI $1640+10 \%$ FCS for the time points indicated. The cell numbers were counted in a Bürker chamber. Data for mean \pm SEM for 6 to 8 experiments are given. (D) Growth of RIN-Shb and RINneo cells in $0.1 \%$ serum. Cells $(30,000)$ were plated and cultured for the time points indicated in RPMI $1640+0.1 \%$ FCS and counted as in C. Data for mean \pm SEM for 5 experiments are given. ${ }^{*} p<0.05$ when compared with the value for RIN-Shb at $24 \mathrm{hr}$ using a paired Students' $t$-test.

cell survival (6). It is currently not clear how Shb exerts these effects, except that these are independent of elevated content of c-myc and p53 (6). Presently, the most obvious effects of Shb in vivo are an increased rate of glucose disappearance and an increased $\beta$-cell mass, 

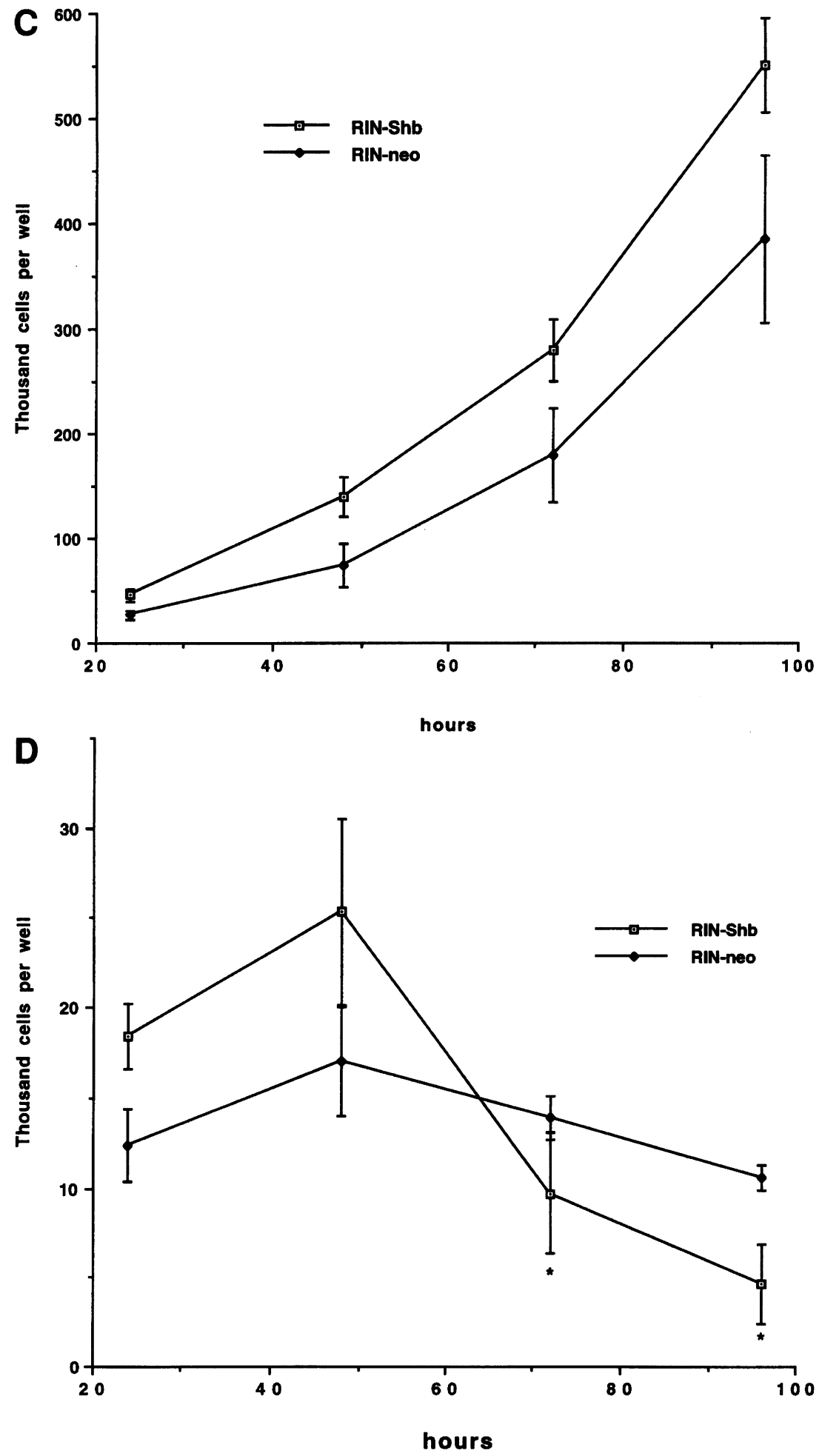

Fig. 5. Continued

the former likely being a consequence of the latter. It is clear, however, that this increase in $\beta$-cell mass is apparent on day 1 neonatally. It thus results from effects of expression of the transgene on either $\beta$-cell neogenesis from undifferentiated insulin producing precursor cells 

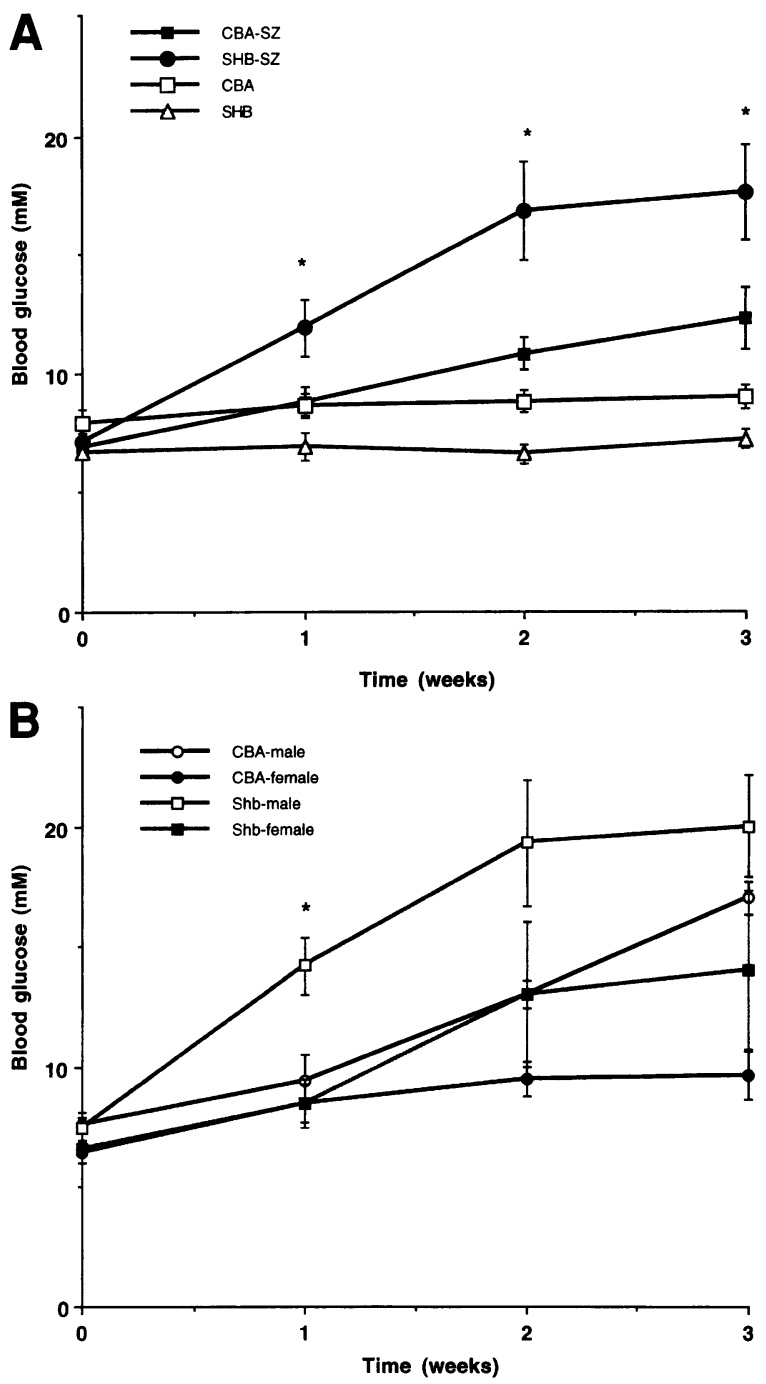

Fig. 6. Blood glucose values for Shb-transgenic and control CBA mice of both sexes after multiple injections of streptozotocin. (A) Mice of both groups were injected with streptozotocin (SZ) or saline and the blood glucose levels were determined immediately before the start of injections and 1,2 , and 3 weeks thereafter. Data for mean \pm SEM are given for 8-11 mice. ${ }^{*} p<0.05$ when tested with an unpaired Students' $t$-test against the corresponding CBA-SZ value. (B) Role of gender in the development of hyperglycemia in Shb-transgenic and CBA control mice after multiple streptozotocin injections. Blood glucose determinations were performed as in A. Data for mean \pm SEM are given. ${ }^{*} p<0.05$ when tested against the corresponding value for CBA-male mice using an unpaired Students' $t$-test. Male CBA, $n=4$; female CBA, $n=7$; male Shb, $n=6$; female Shb, $n=4$.

or increased $\beta$-cell replication during late embryonic stages. The lack of effect of the Shbtransgene on $\beta$-cell DNA synthesis at 3 months of age is consistent with this notion, since the increased $\beta$-cell mass apparent immediately after birth remains proportionately increased for at least 6 months without being further accentuated. However, the in vitro data showing increased rates of islet cell apoptosis in $1 \%$ serum, as well as after culture in the presence of cytokines, indicate that Shb also plays a role in $\beta$-cell survival. Under physiological in vivo conditions, we have not detected apoptosis of $\beta$-cells in Shb-transgenic mice (results not shown). These findings are reminiscent of what was observed in NIH3T3 cells overexpressing Shb (6); apoptosis induced by culture in a low-serum concentration was completely reversed by PDGF or $10 \%$ serum. It is conceivable that, in vivo, such suppression of $\beta$-cell apoptosis occurs in the Shb-transgenic mice. The data obtained in RINm5F cells also support the view that Shb has dual effects on cell viability. Whereas cell proliferation in RINm5F cells overexpressing $\mathrm{Shb}$ in $10 \%$ serum was excellent, cell viability in the presence of 50 $\mathrm{mM}$ nicotinamide or $0.1 \%$ serum was decreased.

Shb-transgenic mice are more sensitive to multiple injections of the $\beta$-cell toxin streptozotocin in vivo. This finding is in line with the in vitro data on both islets and RINm5F cells, in which decreased survival in response to exposure to low serum, cytokines, and nicotinamide was observed in cells overexpressing Shb. The data raise the possibility that Shb participates in death signaling in vivo whenever $\beta$-cells are under stress in a hostile environment.

Insulin secretion in response to glucose in vitro was also enhanced and appears to at least partly reflect an increased islet $\beta$-cell mass with concomitant increases in insulin and DNA content. On the other hand, there may be an actual sensitization of the secretory machinery in response to glucose as well, and this could also be operating in vivo. Thus, the enhanced glucose disappearance after glucose injections could partly derive from an increased $\beta$-cell mass, but could also reflect a sensitized secretory machinery.

The Shb-induced embryonic increase in $\beta$-cell mass at birth provides a unique animal model to evaluate the significance of an increased $\beta$-cell mass for glucose homeostasis under various conditions. The effect of Shb overexpression is targeted to the $\beta$-cell and thus the 
increased $\beta$-cell mass is not primarily a consequence of other phenomena. Furthermore, increased $\beta$-cell mass is not accentuated further as the animals age. Finally, the islets display no signs of impaired insulin secretory responses under the conditions tested. The only detrimental effect that we have observed in Shb-transgenic mice is the increased sensitivity to certain toxic or stressful conditions.

In summary, the combined data suggest a role of Shb in $\beta$-cell destruction. Since the total $\beta$-cell mass is of relevance for the development of type 1 diabetes mellitus and mechanisms of $\beta$-cell repair/regeneration have been proposed to play a role in the final outcome of the disease (22), the participation of Shb in such responses may be highly significant. Although we have observed increased apoptosis in Shb overexpressing cells, we have not excluded the possibility that Shb under certain conditions protects against cell death, as was previously observed in PDGF-treated NIH3T3 cells overexpressing Shb. Relating this to normal in vivo circumstances, Shb may promote an increase in $\beta$-cell mass, particularly during late embryonic development. Furthermore, the data also suggest that, under pathological conditions such as cytokine-induced stress or after exposure to $\beta$-cell toxins, Shb may facilitate the disappearance of $\beta$ cells. The regulation of such a balance between death and survival could be of relevance to the development of type 1 diabetes.

\section{Acknowledgments}

We are grateful for the technical assistance of Ing-Britt Hallgren and Ing-Marie Mörsare. Transgenic mice were generated under the supervision of Dr. Dan Holmberg, Umeå University, Umeå, Sweden. This study was supported by the Juvenile Diabetes Foundation International, the Swedish Medical Research Council (12X-10822, 12X-11564, 12X-8273, 12P-10739), the Swedish Diabetes Association, the Novo-Nordisk Foundation, the Göran Gustafsson Foundation, and the Family Ernfors Fund.

\section{References}

1. Swenne I (1983) Effects of aging on the regenerative capacity of the pancreatic B-cell of the rat. Diabetes 32: 14-19.
2. Bouwens L, Klöppel G (1996) Islet cell neogenesis in the pancreas. Virchows Arch. 427: 553-560.

3. Welsh M, Mares J, Karlsson T, Lavergne C, Bréant B, Claesson-Welsh L (1994) Shb is a ubiquitously expressed Src homology 2 protein. Oncogene 9: 19-27.

4. Karlsson T, Songyang Z, Landgren E, et al. (1995) Molecular interactions of the Src homology 2 domain protein Shb with phosphotyrosines, tyrosine kinase receptors and Src homology 3 domain proteins. Oncogene 10: 1475-1483.

5. Welsh, M, Songyang Z, Frantz JD, et al. (1998) Stimulation through the $\mathrm{T}$ cell receptor leads to interactions between $\mathrm{Shb}$ and several signaling proteins. Oncogene 16: 891-901.

6. Karlsson T, Welsh M (1996) Apoptosis of NIH3T3 cells expressing the Src homology 2 domain protein Shb. Oncogene 13: 955-961.

7. Karlsson T, Kullander K, Welsh M (1998) The Src homology 2 domain protein Shb transmits bFGFand NGF-dependent differentiation signals in PC12 cells. Cell Growth Differen. 9: 757-766.

8. Hanahan D (1985) Heritable formation of pancreatic $\beta$-cell tumours in transgenic mice expressing recombinant insulin/simian virus 40 oncogenes. Nature 315: 115-122.

9. Rabinovitch A (1993) Roles of cytokines in IDDM pathogenesis and islet $\beta$-cell destruction. Diabetes Rev. 1: 215-240.

10. Sandler S, Eizirik DL, Sternesjö J, Welsh N (1994) Cytokines and pancreatic B-cell function. In: Insulin Secretion and Pancreatic B-Cell Research. Flatt PR, Lenzen S (eds). Smith-Gordon, West Sussex, UK, pp. 553-558.

11. Mandrup-Poulsen $\mathrm{T}$ (1996) The role of interleukin-1 in the pathogenesis of IDDM. Diabetologia 39: 379-386.

12. Andersson A (1978) Isolated mouse pancreatic islets in culture: effects of serum and different culture media on the insulin production of the islets. Diabetologia 14: 397-404.

13. Welsh N, Eizirik DL, Bendtzen K, Sandler S (1991) Interleukin- $1 \beta$-induced nitric oxide production in isolated rat pancreatic islets requires gene transcription and may lead to inhibition of the Krebs cycle enzyme aconitase. Endocrinology 129: 31673173.

14. Welsh N, Margulis B, Borg LAH, et al. (1995) Differences in the expression of heat-shock proteins and antioxidant enzymes between human and rodent islets: implications for the pathogenesis of insulin-dependent diabetes mellitus. Mol. Med. 1: 806-820.

15. Gavrieli Y, Sherman Y, Ben-Sasson SA (1992) Identification of programmed cell death in situ via specific labeling of nuclear DNA fragmentation. J. Cell. Biol. 119: 493-501.

16. Erlandssen SL, Parsons JA, Van Orden DE, Van 
Orden LS (1975) A modification of the unlabeled antibody enzyme method using heterologous antisera for light microscopic and ultrastructural localization of insulin, glucagon and growth hormone. J. Histochem. Cytochem. 23: 666-677.

17. Korsgren O, Jansson L, Eizirik DL, Andersson A (1991) Functional and morphological differentiation of fetal porcine-like cell clusters after transplantation into nude mice. Diabetologia 34: 379386.

18. Ikkos D, Luft $R$ (1957) On the intravenous glucose tolerance test. Acta Endocrinol. 25: 312-334.
19. Saldeen J, Welsh N. (1998) Nicotinamide-induced apoptosis in insulin producing cells is associated with cleavage of poly(ADP-ribose) polymerase. Mol. Cell. Endocrinol. 139: 99-107.

20. Like AA, Rossini AA (1976) Streptozotocin-induced pancreatic insulitis: a new model of diabetes mellitus. Science 193: 415-417.

21. Heldin $\mathrm{CH}$ (1995) Dimerization of cell surface receptors in signal transduction. Cell 80: 213-223.

22. Eizirik DL, Sandler S, Palmer JP (1993) Repair of $\beta$-cells. A relevant phenomenon in early IDDM? Diabetes 42: 1383-1391. 